\title{
Correction to: The Influence of Woman's Mastectomy on Breathing Kinematics
}

Frantisek Lopot, David Ravnik, Klara Koudelkova, Petr Kubovy, and Petr Stastny

\section{Correction to:}

\section{Chapter "The Influence of Woman's Mastectomy on Breathing Kinematics" in: K. Arkusz et al. (Eds.): Biomechanics in Medicine and Biology, AISC 831, https://doi.org/10.1007/978-3-319-97286-2_3}

In the original version of the book, the second author name "David Rawnik" should be corrected as "David Ravnik" in chapter "The Influence of Woman's Mastectomy on Breathing Kinematics". The correction chapter and the book have been updated with the change.

\footnotetext{
The updated online version of this chapter can be found at https://doi.org/10.1007/978-3-319-97286-2_3 